\title{
Ser e devir: Butler leitora de Beauvoir*
}

Carla Rodrigues**

\section{Resumo}

Neste artigo, parto de uma quase-homofonia possível com a consagrada frase de Simone de Beauvoir (on ne n'ait pas femme, on devient) a fim de operar com a radicalidade do seu pensamento, esta que Judith Butler dirá que a própria filósofa francesa não foi capaz de antecipar. Essa radicalidade como potência do pensamento de Beauvoir é o que anima o percurso, cujo objetivo final é desmontar a falácia da chamada "ideololgia de gênero" e acentuar a força da filosofia de Beauvoir no contexto político contemporâneo.

Palavras-chave: Simone de Beauvoir, Judith Butler, Teoria Feminista, Existencialismo, Liberdade.

\footnotetext{
* Recebido em 20 de agosto de 2019, aceito em 31 de outubro de 2019.

** Professora no Departamento de Filosofia da UFRJ, pesquisadora no Programa de Pós-Graduação em Filosofia (IFCS), Universidade Federal do Rio de Janeiro, Rio de Janeiro, RJ, Brasil. Bolsista de produtividade da Faperj com o projeto "Judith Butler: do gênero à violência de estado", do qual este artigo faz parte. carla.ifcs@gmail.com / http://orcid.org/0000-0002-1421-5120
} 
"Aparentemente, a teoria de Beauvoir trazia consequências radicais, que ela própria não antecipou" (Judith Butler)

Introdução

Começo retomando Simone de Beauvoir no original a fim de partir de uma quase-homofonia entre duas frases "on ne nait pas femme, on devient" e "on n'est pas femme, on devient". Em português, perco o recurso sonoro quando traduzo assim: "Não se nasce mulher, se devém" e "Não se é mulher, se devém". Entre perdas e ganhos, tenho também a oportunidade de operar uma substituição do verbo tornar, já estabelecido, para o verbo devir, aproximando meu vocabulário do argumento que quero desenvolver: em Simone de Beauvoir, a mulher já está deslocada do ser para o devir, consequência das aberturas proporcionadas pelo pensamento existencialista francês do qual ela é uma das expoentes. Poderia dizer, por exemplo, que "não se nasce mulher, se devém mulher" é uma hipótese de tradução feminista de "a existência precede a essência", síntese do existencialismo francês dos anos 1940/50. Esse movimento de devir-mulher supõe desontologizar a existência (on ne naît/on n'est pas femme) para lançá-la numa experiência de "liberdade situada", tema tão caro à obra de Beauvoir.

Na minha perspectiva, a passagem do ser para o devir que se dá em Beauvoir é radicalizada em Butler, de modo que a frase, se reescrita por ela, ficaria "On nait/n'est pas, on devient en différance", ou "Não se nasce/não se é, se devém em diferenciação". A possibilidade da retirada da palavra mulher seria a radicalidade já presente no pensamento de Beauvoir, mas não percebida por ela, como me refiro na epígrafe e aqui repito como citação: "Aparentemente, a teoria de Beauvoir trazia consequências radicais, que ela própria não antecipou" (Butler, 1990:22, tradução minha). O acréscimo da noção de différance é uma proposição minha a fim de acentuar o movimento 
permanente que já está no uso do verbo devir, mas aqui se radicaliza.

Arrisco-me mesmo a dizer que parte dos problemas criados em Gender Trouble não teriam sido possíveis sem as aberturas proporcionadas pela filosofia de Beauvoir, embora não apenas. Em um primeiro momento, Butler se vale de Beauvoir para radicalizar a desontologização do sujeito que já se anunciava na filósofa francesa. É o que me permite dizer que, na filosofia de Butler, o devir-mulher é insuficiente, porque passará a ser preciso interrogar que essência ou substância poderia oferecer a garantia que um corpo nascido fêmea venha a devir mulher. Não se nasce um corpo, se devém um corpo; não se é um corpo, se devém um corpo, e esse devir se dá a partir de todos os marcadores que lhe são inscritos e lançados na temporalidade. Para propor o deslocamento do ser para o devir em Beauvoir e em Butler, este artigo vai percorrer, ainda que de forma breve, o problema do sujeito nas duas autoras, ambas leitoras do hegelianismo francês do século $\mathrm{XX}$, para em seguida discutir o uso do conceito de gênero por Butler e o problema de sua atribuição à filosofia de Beauvoir. Por fim, pretendo chegar à proposição de gênero como mais um dos marcadores corporais que introduzem o tema da interseccionalidade na obra de Butler e, com isso, ao mesmo tempo amplia e rebaixa o conceito de gênero, de modo a torná-lo apenas mais um dos marcadores que separam as vidas vivíveis das vidas matáveis. Essa mudança complexifica as reivindicações do movimento feminista, ao mesmo tempo em que as amplia.

\section{Sujeito}

Até que Alexandre Koyré publicasse, em 1931, Hegel em Iena na Revue d'histoire de la philosophie, os estudos sobre Hegel na filosofia francesa praticamente não existiam, à exceção da publicação, quase desapercebida, de Le malheur de la conscience dans la philosophie de Hegel, de Jean Wahl. Na década de 1940, foram os cursos de Alexandre Kojève e, na sequência, os de seu aluno, Jean Hyppolite, os grandes marcos na leitura francesa de 
Hegel, com a publicação de Introduction à la lecture de Hegel, do primeiro, e de Genèse et Structure de la Phénoménologie de l'Esprit de Hegel, do segundo. Hyppolite foi orientador da tese de doutorado de Derrida sobre a fenomenologia de Husserl, daí a minha referência inicial ao termo différance. ${ }^{1}$

É nesse ambiente que a filosofia de Simone de Beauvoir se desenvolve, em diálogo tanto com o existencialismo quanto com pensadores críticos das filosofias do sujeito. Desde a introdução de $O$ segundo sexo, Beauvoir está preocupada com a atribuição da mulher como figura de alteridade, como o Outro do homem: "A mulher determina-se e diferencia-se em relação ao homem, e não este em relação a ela; a fêmea é o inessencial perante o essencial. O homem é o Sujeito, o Absoluto; ela é o Outro" (Beauvoir, 2009:17). Nesse ponto, a autora se refere a uma passagem em que o filósofo Emmanuel Lévinas (1947) está propondo pensar a diferença sexual como uma dualidade de dois termos complementares. Beauvoir identifica aí uma visão androcêntrica $e$ um privilégio do masculino em determinar a mulher como Outro, mantendo assim o feminino em posição secundária. Tatsuro Ushida (2001), comentador da obra de Emmanuel Lévinas, argumenta que $O$ Segundo Sexo teria sido escrito em grande parte para refutar as ideias de Lévinas acerca do feminino, entendido, pelo filósofo de tradição judaica, como complementar ao masculino, e portanto necessariamente diferente. Ainda segundo Ushida, as proposições de Lévinas acerca do feminino como acolhimento, desenvolvidas na sua obra principal (Lévinas, 1961), seriam uma resposta não apenas às críticas de Beauvoir, mas sobretudo posicionamento em relação à reivindicação de

1 Observo a influência de quatro Hs na formação filosófica de Derrida: Husserl, sobre quem realizou pesquisa de mestrado e doutorado; Heidegger, de quem herdou a leitura de Hegel, as críticas a Husserl e questões como a destruição da metafísica - por Derrida transformada em desconstrução da metafísica - e como o problema da diferença ôntico-ontológica - por Derrida desdobrada na noção de différance; Hegel, autor fundamental no desenvolvimento da noção de différance, e Hyppolite, um importante autor na história da recepção francesa de Hegel. 
igualdade entre homens e mulheres. Para Lévinas, pensar a diferença era, naquele momento, um gesto ético-político mais importante do que pensar a igualdade, que na sua interpretação havia fracassado (Rodrigues, 2011). ${ }^{2}$

A questão da mulher como figura da alteridade reaparece no momento em que Beauvoir dialoga com Hegel, especificamente com a dialética entre o senhor e o escravo, aquele ponto chave da Fenomenologia do espírito (2011) em que a consciência se torna consciência de si a partir de uma interdependência entre o eu e o outro. A passagem foi interpretada por Beauvoir como mais um movimento de atribuir à mulher o lugar de dependente, presa à vida animal, incapaz de ascender ao campo da cultura. Ela parte do argumento de que na dialética entre o senhor e o escravo, Sujeito é o Absoluto e o Outro é o imanente, o que significaria, para ela, a manutenção da ideia de que o homem é o sujeito e a mulher é o outro, aquela que se constitui numa identidade de oprimida ou secundária. As mulheres não seriam, julga Beauvoir, capazes de se identificar como origem da alteridade nem de obter reconhecimento sem se constituírem, elas também, como sujeitas. Destinada ao lugar de "outro", a mulher não poderia, ainda seguindo o argumento de Beauvoir, caminhar pelo roteiro hegeliano a fim de reivindicar reconhecimento.

Nesta crítica, Beauvoir entra para a história da filosofia como a primeira pensadora a indicar não haver roteiro para contemplar a constituição da mulher como sujeita, já que mesmo os filósofos que formularam um conceito de sujeito a partir de sua relação com a alteridade ofereciam apenas duas possibilidades: as mulheres estavam impedidas de se tornar sujeitos; as mulheres deveriam seguir o único roteiro disponível, aquele que formava sujeitos homens $e$ as confinava como o outro do homem, relegando a mulher ao lugar de "segundo sexo" que dá título ao

2 A respeito do debate entre Beauvoir e Lévinas, que não será desenvolvido aqui, permito-me referir ao artigo "A costela de Adão: diferenças sexuais a partir de Lévinas" (Rodrigues, 2011). 
livro. A experiência de liberdade pensada no âmbito do existencialismo só estaria, portanto, acessível ao homem.

Com meu o recurso inicial à homofonia, consigo pensar que Beauvoir estaria enfrentando dois problemas inseparáveis: não se nasce mulher, porque a mulher é forjada pela cultura; não se é mulher, porque se não há uma essência para o humano, também não pode haver uma essência para a mulher. Será preciso, portanto, clamar pelo direito à existência no sentido que o existencialismo dá ao termo. Entendo que é por isso que parte do debate de Beauvoir com Hegel diz respeito à distinção entre atividade e função e ao par imanência/transcendência. Parir, amamentar e cuidar seriam funções naturais nas quais, argumenta Beauvoir, a mulher não teria motivos para afirmar sua existência, mas apenas para suportar passivamente seu destino biológico. Beauvoir diferencia o poder do homem em alimentar do destino da mulher de amamentar. Enquanto o homem alimenta como atividade, transcendendo a sua condição animal, a mulher ficaria restrita à mera função natural. Com isso, argumenta ela, não é a vida natural que tem para a humanidade um valor supremo, mas a vida que serve a fins mais importantes do que ela própria.

A desgraça da mulher consiste em ter sido biologicamente
votada a repetir a vida, quando a seus próprios olhos a vida
não apresenta em si suas razões de ser e essas razões não
são mais importantes do que a própria vida (Beauvoir,
2009:103).

Dito de outro modo, não é a natureza, mas a cultura que faz com que a vida tenha valor e, mais, também não é a natureza a origem da vida que tem valor. Nos termos postos por Beauvoir, a pura vida natural - atribuída às mulheres, por isso Butler dirá que só a mulher tem um corpo corpo - é foracluída como origem da vida cultural com valor.

O mesmo Hegel francês foi o objeto da tese de doutorado da filósofa Judith Butler, que se dedicou a pesquisar, na recepção francesa do filósofo alemão, a relação entre desejo e 
reconhecimento a partir da seguinte pergunta: a que se deve que a constituição do sujeito suponha uma relação radical e constitutiva com a alteridade? (Butler, 1999:XIV). Vale lembrar que Butler está engajada nas mesmas da Fenomenologia do Espírito que veem o sujeito em permanente processo de expropriação; sujeito cuja constituição é marcada pelo risco de se perder de si mesmo, em deslocamentos para os quais não há momento definitivo de restauração e que aqui estou provocativamente chamando de différance, trazendo à tona uma relação entre Hegel e Derrida que este insistiu em mitigar (Safatle, 2014). ${ }^{3}$

Valendo-se de uma leitura que eu poderia chamar de "desconstrucionista" do livro de Beauvoir, Butler traz perturbações novas para o processo de "desontologização da existência", repensando sujeito e sua relação com a alteridade e, em grande medida, concordando com Beauvoir. Na leitura de Butler,

\begin{abstract}
(...) em Beauvoir, o "sujeito", na analítica existencial da misoginia, é sempre já masculino, fundido com o universal, diferenciando-se de um "Outro" feminino que está fora das normas universalizantes que constituem a condição de pessoa, inexoravelmente "particular", corporificado $e$ condenado à imanência. Embora veja-se frequentemente em Beauvoir uma defensora do direito de as mulheres se tornarem de fato sujeitos existenciais, e portanto, de serem incluídas nos termos de uma universalidade abstrata, sua posição também implica uma crítica fundamental à própria descorporificação do sujeito epistemológico masculino abstrato (Butler, 2003:31).
\end{abstract}

Butler quer chamar a atenção para o problema de que o sujeito universal abstrato nega sua marcação corporal e projeta essa corporificação - renegada e desacreditada, para citar os termos da autora - na esfera feminina. Só a mulher tem um corpo, $e$ este funciona como fundamento para restrições, enquanto o

3 O Hegel "mitigado" na filosofia de Derrida é uma expressão que tomo emprestado da interlocução com Vladimir Safatle. 
corpo masculino torna-se o "instrumento incorpóreo de uma liberdade ostensivamente radical" (Butler, 1990:31).

Gostaria de retomar argumentos que mobilizei nas minhas pesquisas de mestrado e doutorado, trabalho em que confrontei a crítica ao sujeito em Butler com a crítica ao sujeito na filosofia de Jacques Derrida (Rodrigues, 2008; 2011). O debate que estabeleci então dizia respeito à compreensão de identidade como ipseidade, como Eu idêntico a si mesmo, fechado à alteridade, questão que mobilizava autores críticos à centralidade do conceito de sujeito $e$ a importância decisiva do tema para a teoria feminista se confrontar com uma suposta neutralidade do sujeito. Grande parte da minha pesquisa inicial se deu na investigação da ironia contida nessa afirmação de Butler: "Há o refrão de que, justamente agora, quando as mulheres começam a assumir o lugar de sujeitos, as posições pós-modernas chegam para anunciar que o sujeito está morto" (Butler, 1998:23).

Se para Beauvoir era fundamental que as mulheres também pudessem ter existência - sem o que não haveria o prometido exercício de liberdade do existencialismo -, para Butler tornaramse políticos os próprios termos em que a existência do sujeito era afirmada. Beauvoir escreve em um contexto em que a filosofia ainda sustentava um modelo de sujeito universal abstrato sob o qual subjaz a sobreposição entre neutralidade e masculino. Cinquenta anos depois, Butler já escrevia em um contexto em que o conceito de sujeito havia sido posto em xeque por tudo que carregava de excludente. No campo da crítica ao sujeito ontológico e sua necessária relação com a teoria feminista, recorro a uma passagem de uma entrevista em que Derrida está discutindo a quem serve o conceito de sujeito:

A autoridade e a autonomia (pois mesmo que esta se submeta à lei, este assujeitamento é liberdade) são, por este esquema, antes concedidas ao homem (homo $e$ vir) do que à mulher, $e$ antes à mulher do que ao animal. $\mathrm{E}$, é claro, ao adulto antes do que à criança. A força viril do macho adulto, pai, marido ou filho (o cânone da amizade, demonstrei-o noutro lugar, privilegia o esquema fraternal) 
pertence ao esquema que domina o conceito de sujeito (Derrida, 2018:178/179).

No meu argumento, o caminho de Butler - a crítica radical à necessidade de a política feminista se fundamentar numa base única e permanente, que só funcionaria dentro da ideia de identidade - é defender a hipótese de que o sujeito do feminismo não desaparece, mas passa a ser entendido como imprevisível $e$ indeterminado e ambíguo, para acrescentar um termo do vocabulário de Beauvoir que caberia muito bem aqui (Butler, 1998:23). "A desconstrução da identidade não é a desconstrução da política; ao invés disso, ela estabelece como políticos os próprios termos pelos quais a identidade é articulada", escreve ela (Butler, 2003:213), para perguntar: "se a reivindicação da emancipação não é feita pelo sujeito feminino, a quem emancipar?” (Butler, 1990:79). Entendo que Butler está propondo deslocar a política feminista do campo do humanismo - que pressupõe o sujeito como identidade fixa - para interrogar os próprios termos da política, quais sejam, o de criar um pressuposto fixo - o sujeito - a uma realidade instável - os/as sujeitos/as.

Do gênero à interseccionalidade

Se é verdade que no debate sobre a relação entre sujeito $e$ alteridade Beauvoir e Butler compartilham referências, é verdade também que quando Butler se vale de Beauvoir para ir além do que a própria autora francesa havia formulado faz uma ultrapassagem rápida demais do sujeito ao gênero. Como tão bem observa Maria Luiza Femenias (2012), Butler recorre à formulação "On ne nait pas femme, on devient" para, longo em seguida, operar uma desconstrução do par sexo/gênero, sem considerar que o conceito de gênero não consta na obra da filósofa francesa, até por ser posterior. Mas é verdade também que, ainda que a posteriori, as teorias feministas vieram associar a Beauvoir uma das origens do conceito de gênero como construção social, marcador da assimetria das relações entre homens e mulheres 
(Heilborn; Rodrigues, 2013; 2018). ${ }^{4} \mathrm{Na}$ minha leitura, entre os inúmeros interlocutores que Beauvoir confronta em "O segundo sexo", está a concepção moderna que o filósofo J.J. Rousseau atribui à diferença sexual, alocando os homens como sujeitos de direitos na vida pública $e$ as mulheres como assujeitadas à vida privada, compreendida como sustentáculo para que o homem pudesse exercer sua cidadania e participar do contrato social.

Beauvoir estaria, portanto, demonstrando como foi preciso forjar, ao longo do percurso histórico moderno, educação, cultura $e$ vida social que mantivessem a diferença sexual muito bem delimitada. Nesse sentido, sua contribuição para pensar a passagem da fêmea que nasce, como dado biológico de nascimento, para a mulher que devém "do conjunto da civilização que elabora esse produto intermediário entre o macho e o castrado que qualificam de feminino" (Beauvoir, 2009:361), é fundamental para a elaboração do conceito de gênero. No entanto, Beauvoir não formula o par sexo/gênero contra o qual Butler direciona sua crítica, originada em diferentes caminhos que se entrecruzam. No que diz respeito à filosofia de Butler, uma pista importante a perseguir é a antropologia de Gayle Rubin (2017).

Rubin é uma das interlocutoras principais na crítica ao sistema sexo/gênero, apontada pela antropóloga tanto em confronto com a concepção das estruturas elementares do parentesco em Lévi-Strauss quanto com a proposição freudiana de Complexo de Édipo. Quinze anos depois do ensaio de Rubin, Butler acrescenta um novo problema ao par sexo/gênero a fim de indicar que "gêneros inteligíveis" seriam apenas os sustentados em relações de coerência e continuidade entre sexo, gênero, prática sexual e desejo, o que só seria possível se pudéssemos discernir os elementos biológicos, psíquicos, discursivos e sociais. O problema da inteligibilidade vai reaparecer dez anos depois em $O$ clamor de

${ }^{4}$ Gostaria de me referir ao debate sobre o conceito de gênero que venho empreendendo com a profa. Maria Luiza Heilborn, tanto em sala de aula quanto em artigos em comum: "Gênero e pós-gênero: um debate político" e "Gênero: breve história de um conceito". 
Antígona (2014) e se manter no debate acerca dos elementos distintivos entre as vidas vivíveis das vidas matáveis. Outra interlocura importante em Gender Trouble é a pensadora Monique Wittig (1993) - cuja crítica a Beauvoir antecede a de Butler, a quem ela segue bem de perto - a fim de chegar ao seguinte ponto: pensar a diferença sexual em termos de heterossexualidade compulsória seria muito mais potente do que pensá-la apenas a partir do conceito de gênero, ainda preso ao binarismo masculino/feminino.

Para Beauvoir - como para Wittig - a identificação das
mulheres com o "sexo" é uma fusão da categoria das
mulheres com as características ostensivamente
sexualizadas dos seus corpos e, portanto, uma recusa a
conceder liberdade e autonomia às mulheres, tal como as
pretensamente desfrutadas pelos homens. Assim, a
destruição da categoria do sexo representaria a destruição
de um atributo, o sexo, o qual, por meio de um gesto
misógino de sinédoque, tomou o lugar da pessoa, do cogito
auto-determinador. Em outras palavras, só os homens são
"pessoas" e não existe outro gênero senão o feminino
(Butler, 2003:41).

Nesse momento, pela leitura de Wittig, a crítica ao sujeito universal abstrato se funde à percepção da insuficiência do conceito de gênero por seu binarismo, dando a impressão de que a crítica de Butler ao gênero arrastaria de roldão a proposição de Beauvoir. Volto a Femenías:

Butler não pretende compreender a posição fenomenológica e existencialista de Beauvoir, não é uma exegeta do pensamento da filósofa francesa. Ao contrário, me parece que ela toma como ponto de partida para desenvolver sua própria teoria e assim fundamentar uma concepção performativa de "agência" $e$, em um sentido amplo, de "política" (Femenías, 2012:313). 
Butler desconstrói o par binário sexo/gênero, mas não para destruí-lo - o que levaria à compreensão de que, se a dualidade sexo/gênero foi fundamental para o movimento do feminismo, sua destruição levaria ao seu abandono. Há uma confusão recorrente entre destruição, desconstrução e crítica. Butler leu Beauvoir não para "renunciar a todas as aberturas proporcionadas" pela pensadora francesa, mas para ir além delas, daí meu argumento que Problemas de gênero não teria sido escrito sem $O$ segundo sexo. Será ainda seguindo Wittig muito de perto que Butler dará o primeiro passo na direção da crítica à identidade de gênero - que no decorrer do livro será deslocada para performatividade de gênero - para dizer que há um problema na "conclusão de que uma pessoa é um gênero e o é em virtude do seu sexo, de seu sentimento psíquico do eu, e das diferentes expressões desse eu psíquico, a mais notável delas sendo a do desejo sexual" (Butler, 1990:141). Podemos pensar que seu gesto político histórico é indicar que não há a verdade do gênero (Butler, 2003:195), assim como Beauvoir havia apontado que não há a verdade do sexo.

No debate sobre o sujeito estava posta a necessidade de discutir a identidade como aquilo que define e circunscreve o $\mathrm{Eu}$; aqui a identidade de gênero já é um problema endereçado à política feminista $e$ as limitações de representar "a mulher". Entra em cena outra autora que, no contexto deste artigo, será de grande ajuda:

(...) é um problema político que o feminismo concorde que a admissão do termo "mulheres" denota uma identidade em comum. Em vez de um significado estável que comanda a concordância das pessoas a que o termo propõe descrever e representar, mulheres, mesmo no plural, se tornou um termo problemático, um lugar de contestação, um motivo de ansiedade. Como sugere o título do livro de Denise Riley, "Am I that name?" [Eu sou esse nome?] ${ }^{5}$, esta

5 Essa também é a pergunta que Desdemona faz a lago quando Otelo a acusa de ser prostituta, já indicando o aspecto trágico da nomeação de um homem em relação à mulher, marcada tanto pelo nome pelo qual é designada quanto pelo 
é uma questão produzida pelas inúmeras possibilidades desse nome e de suas múltiplas significações. Se alguém "é" uma mulher, certamente isso não é tudo que a pessoa é; o termo fracassa ao tentar ser exaustivo, não porque a pré-generificação de uma "pessoa" transcende a parafernália específica do seu gênero, mas porque gênero não é sempre constituído de forma coerente e consistente em contextos históricos diferentes, e porque gênero faz intersecção com modalidades raciais, classistas, étnicas, sexuais e regionais de identidades discursivamente constituídas. Resulta que se tornou impossível separar a noção de "gênero" das interseções políticas e culturais em que invariavelmente ela é produzida e mantida (Butler, 1990:3, tradução minha).

A citação é muito rica para pensar tanto a necessidade de rever os objetivos da política feminista, não mais a ser feita em defesa de uma "identidade de gênero", quanto para indicar o momento de passagem do gênero à interseccionalidade. Butler está dialogando com Denise Riley (1988) que por sua vez está recuperando a famosa interrogação da abolicionista negra Sojourner Truth (1851): "'Eu não sou mulher?". A pergunta vinha acompanhada do problema de as mulheres negras, associadas ao trabalho braçal da escravidão, não poderem se identificar como frágeis e, portanto, não serem reconhecidas como mulheres. Riley começa seu livro deslocando a pergunta de Truth para "eu não sou uma identidade flutuante?", com a qual Butler se alinha quando argumenta que a recusa da identidade "mulheres" seria necessária para o feminismo. Uma das questões em debate na teoria feminista no anos 1980 era o deslocamento do conceito de mulher - que no singular parecia por demais restritivo - para mulheres, que no plural poderia tentar abarcar diferenças irredutíveis: brancas e negras, ocidentais e orientais, ricas $e$ pobres, heterossexuais e lésbicas, apenas para ficar com os

seu patronímico, que também é dado pela relação familiar com o homem, seja o pai ou o marido (Spivak, 1997). 
exemplos mais óbvios. Riley e Butler chegam nessa conversa com o argumento de que apenas substituir "mulher" por "mulheres" não era suficiente, num exercício difícil de romper com a categoria $e$ ao mesmo tempo manter a luta feminista, como se pode ler em Riley:

(...) "mulheres" é uma coletividade volátil, na qual as pessoas do sexo feminino podem ser posicionadas de formas muito diferentes, a aparente continuidade do sujeito "mulheres" não é estável; 'mulheres' como coletividade é sincronicamente e diacronicamente errático, enquanto que para o indivíduo, 'ser mulher' é também inconstante, e não tem base ontológica de sustentação. Ainda assim, deve-se enfatizar que essas instabilidades da categoria são sine qua non para o feminismo, que de outra forma perderia seu objeto, seria despojado de sua luta e, em suma, não teria muita vida (Riley, 1988:2, tradução minha) .

O argumento de Butler é muito próximo a esse, no mesmo exercício difícil de conciliar a crítica ao gênero como construção social, o problema de fazer política feminista supondo uma estabilidade da categoria "mulheres" e nem assim se desfazer do feminismo como bandeira (Riley, 1988). ${ }^{6}$ Ao radicalizar o devir tal qual pensado por Beauvoir, Butler empresta aos sujeitos marcações pela interseccionalidade entre gênero, raça, classe, religião, local de nascimento, lugar de moradia, idade, escolha de objeto sexual, coerência corporal, escolaridade etc. Ser é devir na materialidade de um corpo em constante processo de marcação. O passo seguinte será pensar como essas marcações funcionam para separar as vidas que têm valor das que não têm, o que ela

${ }^{6}$ Há outras proximidades entre Riley e Butler, entre as quais gostaria de destacar: "O que estou sugerindo aqui é que a volatilidade da categoria 'mulher' é tão marcante que torna as alianças feministas tão difíceis quanto inescapáveis" (Riley, 1998:4). Não foi outra coisa que Butler propôs ao falar em "alianças contingentes" e, com isso, abrir o feminismo e, sobretudo o debate sobre gênero, para além da política identitária. 
fará em diálogo com a biopolítica de Michel Foucault e a necropolítica de Achile Mbembe.

Apontamentos finais

A mim parece necessário concluir com uma reflexão que atualize o debate travado por Butler com Beauvoir nos anos 1990 $e$, mais, atualize as questões aqui apontadas. A obra de Simone de Beauvoir é vasta, não começa nem termina nesta frase tão marcante para a história da teoria feminista. A obra de Judith Butler, a esta altura, também é vasta e também não se limita a Problemas de gênero, tendo tido desdobramentos fundamentais para o feminismo contemporâneo. Considero um equívoco produzir disputas entre as duas, sobretudo por estar convencida de que o modo como Butler lê Beauvoir pode nos ensinar algumas coisas sobre métodos de leitura que possam ultrapassar o comentário $e$, mais ainda, funcionar como chave de inteligibilidade para enfrentar questões políticas e epistemológicas. Se posso argumentar que foi esse o gesto primordial da leitura de Butler, é por acreditar que em nada o gesto desmerece a obra de Beauvoir, ao contrário, encontra ali mesmo uma potência que ainda não havia se manifestado.

Se é assim, então talvez eu possa dizer que a atualidade do debate entre Butler e Beauvoir está em localizar naquilo que se produziu há quase 20 anos mais uma chave de inteligibilidade para problemas de gênero na contemporaneidade. Nesse sentido, gostaria de concluir retomando o que tem sido uma dura campanha contra Butler e contra muitas de nós, feministas, acusadas de fazer "ideologia de gênero". Trata-se de uma expressão forjada no âmbito da igreja católica, usada para classificar toda a teoria baseada no conceito de gênero num caminho de destruição dos valores das mulheres e das famílias. Eleita por forças da extrema direita $e$ pelos católicos conservadores como uma das principais "ideólogas do gênero", Butler confronta as definições de "ideologia de gênero" retomando os argumentos de Beauvoir nos seus próprios termos, 
que não me parecem impróprios ao pensamento da filósofa feminista francesa, sobretudo considerando que, em Beauvoir, o corpo nem é totalmente livre, nem totalmente determinado.

Para Beauvoir, o mais crucial é que o "sexo" é desde o começo resultado de uma situação histórica. O "sexo" não está sendo negado, mas está em disputa: nada sobre o que é ser mulher está determinado desde o nascimento, nem o tipo de vida que uma mulher vai levar ou o que ser mulher significa. De fato, muitas pessoas trans são designadas com um sexo no nascimento e vão reivindicar outro ao longo de suas vidas. E se nós pensarmos com base na lógica existencialista da construção social de Beauvoir, alguém pode nascer mulher, mas tornar-se homem (Butler, 2019:s/p).

Esta citação me permite retomar um dos argumentos iniciais, qual seja, o de que a frase de Beauvoir, se reescrita por Butler, poderia ser "on naît/n'est pas, on devient" ou "não se nasce, não se é, se devém em différance". Temos então que nos confrontar com pelo menos dois problemas: 1) não há base natural para o humano, que está em "permanente tensão entre determinismo e liberdade"; 2) o devir é um processo permanente que constitui o humano como inacabado, aberto, perturbado, agitado, inconstante, tremido (Butler, 1990). ${ }^{7}$ Ora, o que pode haver de tão ameaçador em nos descobrirmos menos estáveis? Ainda que essa liberdade seja limitada, porque sempre é, a parcela de liberdade que nos é possível é um pouco maior do que o caminho único do determinismo essencialista. Do meu ponto de vista, o que há de mais ameaçador na homofonia que proponho aqui é o que nos lança na contaminação entre natureza e cultura que a modernidade acreditou ter delimitado, na perturbação entre

\footnotetext{
7 A palavra "trouble" vem do francês arcaico, truble, que pode significar também estado de agitação, perturbação, o que está dentro dos objetivos do livro de Butler, Gender Trouble.
} 
humano e inumano que a história da filosofia tem tentado evitar desde sempre (Safatle, 2015). ${ }^{8}$

Ao retornar a Simone de Beauvoir, vou encontrar as mulheres como aquelas restritas ao campo da imanência, da vida natural, sem reconhecimento como sujeito e portanto sem roteiro de existência possível, sem poder adentrar o campo do humano, este restrito ao homem. Se eu retornar ao modo como Butler lê essa perspectiva de Beauvoir, vou encontrar a hipótese de que não é apenas o gênero que produz essa exclusão da existência identificada pela filósofa francesa, e que a todo corpo pode ser interditado o campo do humano:

\begin{abstract}
O próprio fato de que posso perguntar quais humanos são reconhecidos como humanos e quais não são significa que existe um campo distinto do humano que permanece irreconhecível, de acordo com as normas dominantes, mas que é obviamente reconhecível dentro do campo epistêmico aberto pelas formas contra-hegemônicas de conhecimento. Por outro lado, essa é uma contradição clara: um grupo de humanos é reconhecido como humano $e$ outro grupo de humanos, que são humanos, não é reconhecido como humano (Butler, 2018:43).
\end{abstract}

A distinção entre humano e não humano como marcador de reconhecimento vinha sendo trabalhada a partir da perspectiva de quem tem e quem não tem direito ao luto, marcador que distingue as vidas que contam como vidas e as que não contam. Na minha abordagem, é preciso pensar, tanto no contexto brasileiro, quanto no contexto global de expansão das forças de extrema direita de cunho político e religioso, que todo corpo marcado pelo elemento

\footnotetext{
8 “(...) estamos tão presos à procura de reconhecimento por outros sujeitos, precisamos tanto do assentimento fornecido por eles, que esquecemos como, muitas vezes, o que nos reconforta, o que nos diz realmente que estamos em casa, é ser reconhecido por um animal, é ser reconhecido por algo que, afinal, não é uma consciência de si. Os animais percebem os animais que ainda somos, eles nos lembram de um "aquém" da individualidade a respeito da qual nunca conseguimos nos afastar totalmente" (Safatle, 2015:282).
} 
feminino torna-se um corpo matável, o que tenho chamado de feminicídio estrutural - análogo ao racismo estrutural identificado por Michel Foucault (2005:306). No que estou chamando, ainda como hipótese, de feminicídio estrutural, haveria uma negação absoluta da feminilidade, do feminino e da mulher. Se a crítica ao machismo na vida social se impulsionou a partir das possibilidades que o par sexo/gênero forneceu como chave de inteligibilidade para as formas de hierarquia entre homens e mulheres na sociedade, na cultura e nas relações sociais, pensamentos que, como o de Butler a partir de Beauvoir, nos permitem ir além do par sexo/gênero como fundamento das discriminações podem proporcionar pensar que há algo a mais, o desejo de eliminação de todo corpo marcado pelo feminino, movido por aversão, horror, abjeção. O que estou chamando de feminicídio estrutural estaria presente em todo o aparato institucional, econômico $e$ jurídico que ordena a vida social não apenas para subjugar as mulheres como "gênero", mas também para eliminar o feminino $e$ a feminilidade como marcas dos corpos sexuados. Assim, se a partir de Beauvoir foi possível às mulheres obter reconhecimento como sujeitos, ainda há algo que nos secundariza quando o fundamento natural do feminino entra em perturbação. Abalar esse fundamento natural é expor a arbitrariedade da violência contra certas formas de vida em detrimento de outras, é denunciar que o poder se exerce em nome do necropoder. Por fim, o feminicídio estrutural poderia estar ligado à necessidade de foraclusão do feminino da marca do humano, um feminino cuja perturbação parece precisar ser aniquilada em nome da sustentação de uma razão masculina branca, europeia, colonizadora, heteronormativa, impotente e, por isso mesmo, cada vez mais violenta.

\section{Referências bibliográficas}

BEAUVOIR, Simone. O segundo sexo. Rio de Janeiro, Nova Fronteira, 2009. Tradução: Sérgio Milliet. 
BRANDÃO, Izabel et alii. (org.). Traduções da cultura: perspectivas críticas feministas (1970-2010). Florianópolis, Edufal/Editora Mulheres/ Editora da UFSC, 2017.

BUTLER, Judith. Gender trouble: feminism and the subversion of identity. Nova Iorque, Routledge, 1990.

BUTLER, Judith. Bodies that matter. On the Discursive Limits of "Sex". Nova Iorque, Routledge, 1993.

BUTLER, Judith. Fundamentos contingentes: o feminismo e a questão do "pós-modernismo". cadernos pagu (11), Campinas-SP, Núcleo de Estudos de Gênero-Pagu/Unicamp, 1998, pp.11-42. Tradução: Pedro Maia Soares.

BUTLER, Judith. Subjects of Desire - hegelian reflections in twentiethcentury France. Nova Iorque, Columbia University Press, 1999.

ButLER, Judith. Problemas de gênero - feminismo e subversão da identidade. Rio de Janeiro,Record, 2003. Tradução: Renato Aguiar.

BuTLER, Judith. Precarious life. Londres e Nova Iorque, Verso, 2004.

BUTLER, Judith. O clamor de Antígona.. Florianópolis, Editora da UFSC, 2014. Tradução André Checinel

BUTLER, Judith. Quadros de guerra - quando a vida é passível de luto?. Rio de Janeiro, Record, 2015. Tradução: Sérgio Lamarão e Arnaldo Cunha.

BUTLER, Judith. Vida psíquica do poder. Belo Horizonte, Autêntica, 2017. Tradução Rogério Bettoni.

BUTLER, Judith. Corpos em aliança e a política das ruas. Rio de Janeiro, Record, 2018. Tradução: Fernanda Siqueira Miguens.

BUTLER, Judith. Precisamos parar o ataque a ideologia de gênero. Observatório de Sexualidade e Política SPW, 2019 [http://twixar.me/j9VK-acesso em 20 de abril de 2019]. Tradução: Sonia Corrêa e Carla Rodrigues.

DERRIDA, Jacques. "É preciso comer bem" ou o cálculo do sujeito. Revista Latinoamericana do Colegio Internacional de Filosofia (Número 3), Valparaíso-Chile, 2018, pp.149-185. Tradução: Denise Dardeau e Carla Rodrigues.

FEMENÍAs, María Luisa. A crítica de Judith Butler a Simone de Beauvoir. Revista Sapere Aude, vol. 3, n. 6, Belo Horizonte: 2012, pp.310-339. 
Foucault, Michel. Em defesa da sociedade. São Paulo, Martins Fontes, 2005.

Hegel, Gerog Wilhelm Friedrich. Fenomenologia do espírito. Petrópolis, RJ, Vozes, 2011.

HEILBORN, Maria Luiza; RodRIGUES, Carla. Gênero e pós-gênero: um debate político. Seminário Internacional Fazendo Gênero 10 (Anais Eletrônicos), Florianópolis, 2013.

HEILBORN, Maria Luiza; RODRIGUES, Carla. Gênero: breve história de um conceito. Aprender - Cadernos de Filosofia e Psicologia da Educação, Ano XII, n. 20, Vitória da Conquista, BA, 2018, pp.9-21.

HyPPOLITE, Jean. Gênese e estrutura da Fenomenologia do espírito de Hegel. São Paulo, Discurso Editorial, 1999. Tradução: Silvio Rosa Filho. [1946].

KOJÈVE, Alexander. Introdução à leitura de Hegel. Rio de Janeiro, Contraponto/Eduerj, 2002. Tradução: Estela dos Santos Abreu. [1947].

KOYRÉ, Alexander. Hegel em Iena. Revista Estudos de história do pensamento filosófico. Rio de Janeiro, Forense, 2011. Tradução: Maria de Lourdes Menezes. [1931]

LÉVINAS, Emmanuel. O tempo e o outro. Revista de Fenomenologia, n. 11, Lisboa, Phainomenon, 2005, pp.149-190] Tradução: José Luis Pérez. [1947].

RODRIGUES, Carla. Butler e a desconstrução do gênero. Florianópolis: Revista Estudos Feministas, vol. 3, n. 1, 2005.

RODRIGUES, Carla. O sonho dos incalculáveis: coreografias do feminino e do feminismo a partir de Jacques Derrida. Dissertação (Mestrado em Filosofia), PUC-Rio, Rio de Janeiro, 2008.

RoDRIGUES, Carla. Rastros do feminino: sobre ética e política em Jacques Derrida. Tese (Doutorado em Filosofia), PUC-Rio, Rio de Janeiro, 2011.

Rodrigues, Carla. A função do luto na filosofia política de Judith Butler. In: Correia, A.; HadDoCK-LobO, R.; Silva, C. V. (org.). Deleuze, desconstrução e alteridade. Coleção XV. II Encontro ANPOF, ANPOF, 2017, pp.329-339.

RodRigues, Carla. A costela de Adão: diferenças sexuais a partir de Lévinas. Revista Estudos Feministas, vol. 7, Florianópolis, SC, 2011, pp.371-388. 
RuBIN, Gayle. Tráfico de mulheres: notas sobre a "economia política" do sexo. In: Políticas do sexo. São Paulo, Ubu, 2017. Trad. Jamile Pinheiro Dias.

RILEY, Denise. "Am I that name?" Feminism and the Category of "Women" in History. Basingstoke, UK, Macmillan, 1988.

SAfatle, Vladimir. O Circuito dos Afetos: Corpos Políticos, Desamparo e o Fim do Indivíduo. São Paulo, Cosac Naify, 2015.

SAFATLE, Vladimir. Être juste avec Freud: la psychanalyse dans l'antichambre de De la grammatologie. In: MANIGLIER, Patrice (org.). Le moment philosophique des années 1960 en France. Paris, PUF, 2011. [Fazer justiça a Freud: a psicanálise na antessala da Gramatologia. Tradução Ana Luiza Fay. IN: HADDOCK-LOBO, R. et alii (org). Heranças de Derrida - da linguagem à estética. Volume 2. Rio de Janeiro, NAU Editora, 2014].

SPIVAK, Gayatri. Translator's preface. In: DERRIDA, Jacques. Of Grammatology. Baltimore, The Johns Hopkins University Press, 1997.

WAHL, Jean. Le malheur de la conscience dans la philosophie de Hegel. Paris, PUF, 1929.

Wittig, Monique. One is not born a woman. In: ABElove, H.; BARALE, M. A.; HALPERIN, D. The lesbian and gay studies reader. Nova Iorque, Routdlege, 1993, pp.103-115.

UCHIDA, Tatsuru. Emmanuel Lévinas et la phénoménologie de l'amour. Tokyo, Serika Syobô, 2001. 